\title{
Preventive Effect of Betamipron on Nephrotoxicity and Uptake of Carbapenems in Rabbit Renal Cortex
}

\author{
Yasukuni Hirouchi ${ }^{1}$, Hideo Naganuma ${ }^{1}$, Yukinori Kawahara ${ }^{2}$, Ryuzo Okada ${ }^{1}$, Akira Kamiya ${ }^{3}$, \\ Ken-ichi Inui ${ }^{4}$ and Ryohei Hori ${ }^{5}$

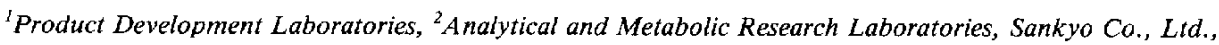 \\ 1-2-58 Hiromachi, Shinagawa-ku, Tokyo 140, Japan \\ ${ }^{3}$ Department of Hospital Pharmacy, School of Medicine, Yamaguchi University, 1144 Kogushi, Ube, Yamaguchi 755, Japan \\ ${ }^{4}$ Department of Hospital Pharmacy, School of Medicine, Tokyo Medical and Dental College, 1-5-45 Yushima, Bunkyo-ku, Tokyo 113, Japan \\ ${ }^{5}$ Department of Hospital Pharmacy, Faculty of Medicine, Kyoto University, 54 Shogoinkawahara-cho, Sakyo-ku, Kyoto 606-01, Japan
}

Received November 29, 1993 Accepted May 20, 1994

\begin{abstract}
The preventive effect of betamipron ( $N$-benzoyl-3-propionic acid: BP) on the renal uptake and nephrotoxicity of carbapenems (panipenem and imipenem) was studied in rabbits. Panipenem, a new carbapenem antibiotic, induced nephrotoxicity at a dose of $200 \mathrm{mg} / \mathrm{kg}$, i.v., but this was less severe than that caused by a single dose of imipenem or cephaloridine. Along with the significant reduction of nephrotoxicity, the uptake of these carbapenems in the renal cortex was remarkably inhibited by simultaneous treatment with BP $(200 \mathrm{mg} / \mathrm{kg}$, i.v.). These results suggest that BP reduces the nephrotoxicity of carbapenems through inhibiting the active transport of carbapenems in the renal cortex. Because of the low toxicity of $\mathrm{BP}\left(\mathrm{LD}_{50}\right.$ in the rat, more than $3,000 \mathrm{mg} / \mathrm{kg}$, i.v. $)$, it was concluded that $\mathrm{BP}$ might be a good candidate for reducing the nephrotoxicity induced by panipenem or imipenem.
\end{abstract}

Keywords: Betamipron (N-benzoyl-3-propionic acid), Panipenem, Imipenem, Nephrotoxicity (rabbit), Renal uptake (rabbit)

Betamipron (BP) is an amino acid derivative that has benzoyl and carboxyl groups in its structure, and it also has very low toxicity in mammals $\left(\mathrm{LD}_{50}\right.$ in the rat, more than $3,000 \mathrm{mg} / \mathrm{kg}$, i.v.). We previously found that BP reduced the nephrotoxicity by cephaloridine (CER), a cephalosporin antibiotic, by inhibiting the intracellular accumulation of CER in renal tubules (1).

Panipenem (PAPM) and imipenem (IPM) are both novel carbapenem antibiotics that cause acute renal injuries in some laboratory animals if they are given at doses much above those required clinically. It is considered that the renal injuries induced by large doses of carbapenems are closely related to high intracellular concentration of the antibiotics in renal tubules. The carbapenems are known to be inactivated by dehydropeptidase-I (DHP-I) located on the brush border of the proximal tubular cells.

Thus, in the present paper, the effect of BP, a new organic anion tubular transport inhibitor (2), on the renal intracellular accumulation and nephrotoxicity of the carbapenems was investigated in rabbits.

\section{MATERIALS AND METHODS}

\section{Evaluation of nephrotoxicity in rabbits}

Male albino rabbits weighing $2.0-3.0 \mathrm{~kg}$ were used in this study. Rabbits were given CER $(75-200 \mathrm{mg} / \mathrm{kg})$, IPM $(100-200 \mathrm{mg} / \mathrm{kg})$, IPM with an equal amount of cilastatin $(150-300 \mathrm{mg} / \mathrm{kg})$, PAPM $(50-400 \mathrm{mg} / \mathrm{kg})$ with or without BP $(50-800 \mathrm{mg} / \mathrm{kg})$ or cefazolin (CEZ, $200-400 \mathrm{mg} / \mathrm{kg}$ ); and the urine was collected every day ( $24 \mathrm{hr}$ from 9:30 to 9:30 on the next day) for measurement of protein and glucose. The intravenous administration of carbapenems and BP were performed simultanously through the ear vein of the rabbit. The rabbits were decapitated five days after administration of the antibiotics, and their kidneys were immediately excised and weighed. They were stained with hematoxylin-eosin or PAS followed by histopathological examination by optical microscopy. Extent of tubular necrosis was evaluated by the following rating system: very slight, very slightly localized tubular necrosis in the kidney; slight, very slight to less than $20 \%$ of tubular necrosis in the kidney; moder- 
ate, $20 \%$ to less than $50 \%$ of tubular necrosis in the kidney; and severe, $50 \%$ or more of tubular necrosis in the kidney.

In vivo uptake study of carbapenems in rabbit renal cortex

Rabbits received the carbapenems with or without BP by a single intravenous administration. The rabbits were decapitated $30 \mathrm{~min}$ after the administration of the drugs, and their kidneys were excised immediately. Renal cortical samples, extending from the surface of the kidney to just above the red junctional zone between the cortex and medulla, were obtained. Cortical samples were weighed and homogenized in $10 \%$ trichloroacetic acid solution, and the concentrations of both carbapenems and BP in the cortex and carotid arterial plasma were measured by an HPLC system with a UV detector.

\section{Analytical methods}

Carbapenems and BP were determined by an HPLC (LC-6A; Shimadzu Co., Kyoto) equipped with a variable wavelength UV detector (SPD-6A, Shimadzu Co.). The conditions of HPLC used for assays of PAPM and BP were as follows: for PAPM: column, YMC-PAC A-312 ODS, $15 \mathrm{~cm} \times 6 \mathrm{~mm}$ I.D. (YMC Co., Ltd., Kyoto); mobile phase, a mixture of acetonitrile / methanol / ammonium acetate (pH 5) / PIC B7 $(1: 6: 92: 1)$; flow rate, 1.5 $\mathrm{ml} / \mathrm{min}$; wavelength $290 \mathrm{~nm}$; column temperature, $40^{\circ} \mathrm{C}$; for BP: column, Cosmosil 5C18-P, $15 \mathrm{~cm} \times 4.6 \mathrm{~mm}$ I.D. (Nacalai Tesque, Inc., Kyoto); mobile phase, acetonitrile
/ acetic acid / water (10:1:89); flow rate, $1.0 \mathrm{ml} / \mathrm{min}$; wavelength, $260 \mathrm{~nm}$; column temperature, $40^{\circ} \mathrm{C}$. IPM was determined by the method of Norrby et al. (3).

Urinary protein was determined according to the Kingsbury-Clark method, and urinary glucose levels were quantitated by a spectrophotometric glucose oxidase kit (Glucose B-Test; Wako Pure Chemical Industries Ltd., Osaka).

\section{Materials}

Imipenem and cilastatin were prepared from commercially available Tienam (Banyu Pharmaceutical Co., Tokyo). Cephaloridine and cefazolin were also purchased from Shionogi \& Co. (Keflordin, Osaka) or Sigma Chemical Co. (St. Louis, MO, USA) and Fujisawa Pharmaceutical Industry Co. (Cefamezin, Osaka). N-Benzoyl-3-propionic acid (betamipron) was purchased from Tokyo Kasei Kogyo Co. (Tokyo). Panipenem was chemically synthesized at the Chemical Research Laboratories, Sankyo Co., Ltd., Tokyo. The other chemicals used for the experiments were of the highest purity available.

\section{RESULTS}

Preventive effect of BP on carbapenem-induced nephrotoxicity in rabbits

The severity of nephrotoxicity induced by PAPM, IPM and CER is shown in Fig. 1. The tubular necrosis induced by PAPM was observed at a dose of $150 \mathrm{mg} / \mathrm{kg}$ or more, that by IPM was observed at doses greater than 100

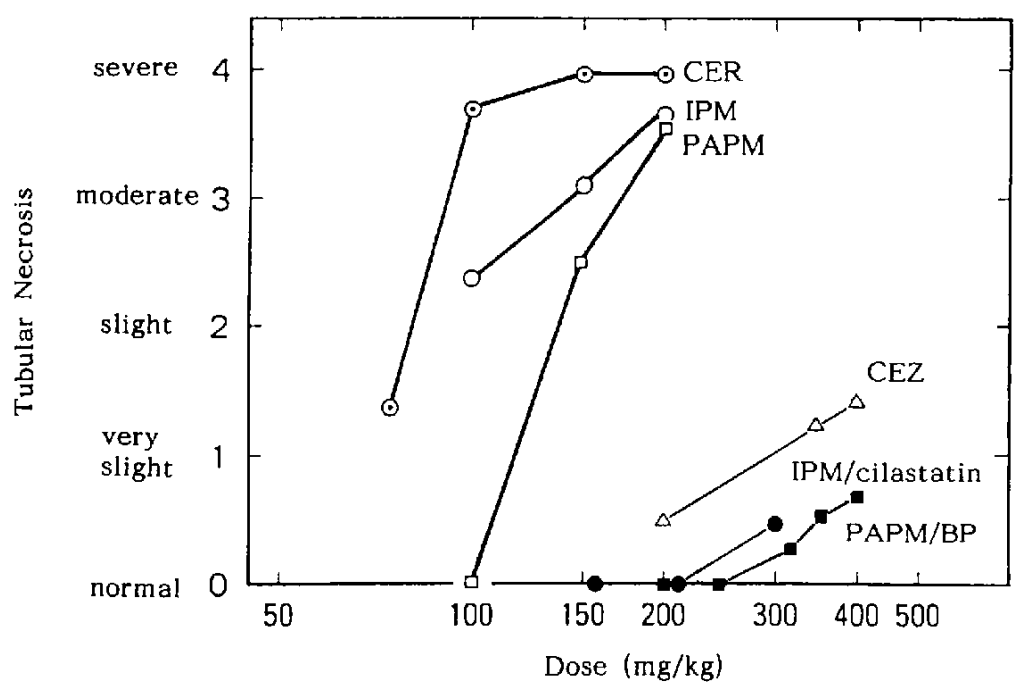

Fig. 1. Intensity of nephrotoxicity induced by carbapenems and cephalosporins in rabbits. Renal tubular necrosis was observed five days after administration of the antibiotics. The extents of tubular necrosis were classified into five levels, and they were given scores of $0,1,2,3$ and 4 points. Each point represents the mean value of five rabbits. IPM/cilastatin and PAPM/BP show coadministrations of equal doses of IPM and cilastatin and equal doses of PAPM and BP, respectively. IPM: imipenem, PAPM: panipenem, CER: cephaloridine, CEZ: cefazolin, BP; betamipron. 
$\mathrm{mg} / \mathrm{kg}$, and that by CER at $75 \mathrm{mg} / \mathrm{kg}$ or more, i.v. in rabbits. However, coadministration of equal amounts of BP markedly decreased the degree of PAPM nephrotoxicity as compared to the effect of PAPM alone. Similar results were obtained after coadministration of equal amounts of cilastatin and IPM. CEZ, which is used as the control in the nephrotoxicity test, induced slight renal tubular necrosis at doses greater than $200 \mathrm{mg} / \mathrm{kg}$. A dose of PAPM at $200 \mathrm{mg} / \mathrm{kg}$ induced swelling, decoloration, ascites and tubular necrosis of the rabbit kidney (Table 1).

The maximal values of both urinary protein and urinary glucose were observed on the 2 nd day after a single

Table 1. Protective effect of betamipron (BP) against the nephrotoxicity induced by panipenem (PAPM) in rabbits

\begin{tabular}{|c|c|c|c|c|c|}
\hline \multirow{2}{*}{$\begin{array}{l}\text { Dose } \\
(\mathrm{mg} / \mathrm{kg})\end{array}$} & \multirow{2}{*}{$\begin{array}{c}\text { Animal } \\
\text { No. }\end{array}$} & \multicolumn{4}{|c|}{ Renal histology } \\
\hline & & Swelling & Decolor & Ascites & Tubular necrosis \\
\hline \multirow{5}{*}{$\begin{array}{l}\text { PAPM } 200 \\
\text { alone }\end{array}$} & 1 & ++ & ++ & - & +++ \\
\hline & 2 & ++ & ++ & - & ++ \\
\hline & 3 & ++ & +++ & ++ & $++t$ \\
\hline & 4 & + & ++ & - & +++ \\
\hline & 5 & + & +++ & - & +++ \\
\hline \multirow{5}{*}{$\begin{array}{l}\text { PAPM } 200 \\
+ \text { BP } 200\end{array}$} & 1 & - & - & - & - \\
\hline & 2 & - & - & - & - \\
\hline & 3 & - & - & - & - \\
\hline & 4 & - & - & - & - \\
\hline & 5 & - & - & - & - \\
\hline
\end{tabular}

Tubular necrosis was observed together with swelling, decoloration and ascites of the kidney following an intravenous dose of PAPM with or without BP in rabbits. The observations were performed 5 days after the administration. The definitions of the symbols are the follows: - normal, + slight, ++ moderate, +++ severe.

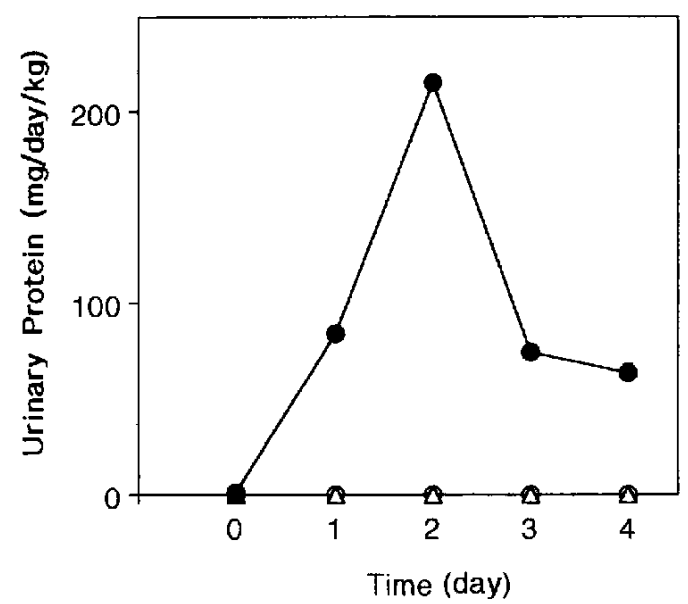

dose of PAPM, and the values slowly decreased thereafter (Fig. 2). These results indicated that renal dysfunction by PAPM ( $200 \mathrm{mg} / \mathrm{kg}$, i.v.) grew gradually up to the 2 nd day after a single administration of the antibiotic, and the function was then restored a few days later. On the other hand, proximal tubular necrosis was observed during two or three days to five days after the administration of PAPM. These renal dysfunctions were, however, reversible in many cases of low dose $(200 \mathrm{mg} / \mathrm{kg})$ administration of the antibiotic.

The coadministration of BP significantly reduced these renal dysfunctions. A single dose of BP $(100-800 \mathrm{mg} / \mathrm{kg})$ did not induce any nephrotoxicity, including tubular necrosis, in three rabbits (data not shown). A simultaneous dose of BP $(200 \mathrm{mg} / \mathrm{kg}$, i.v.) completely prevented the tubular necrosis induced by PAPM $(200 \mathrm{mg} / \mathrm{kg}$, i.v.) (Table 1 ). The values of both urinary protein and urinary glucose remained at normal levels by the coadministration of BP (Fig. 2).

The combination ratio of BP against PAPM was subsequently studied with regard to tubular necrosis in the rabbits. Tubular necrosis was induced by an intravenous dose of $150 \mathrm{mg} / \mathrm{kg}$ or more of PAPM (Fig. 3). A quarterdose combination of BP against PAPM prevented the tubular necrosis induced by less than $200 \mathrm{mg} / \mathrm{kg}$ of PAPM. A half-dose combination of BP against PAPM prevented the tubular necrosis induced by PAPM at a dose of less than $250 \mathrm{mg} / \mathrm{kg}$. An equivalent-dose combination of BP against PAPM prevented the tubular necrosis by less than $300 \mathrm{mg} / \mathrm{kg}$ of PAPM. These results indicated that the carbapenem-induced nephrotoxicity was produced dose-dependently and that the preventive effect of $\mathrm{BP}$ on the carbapenem-induced nephrotoxicity was also dose-dependent.

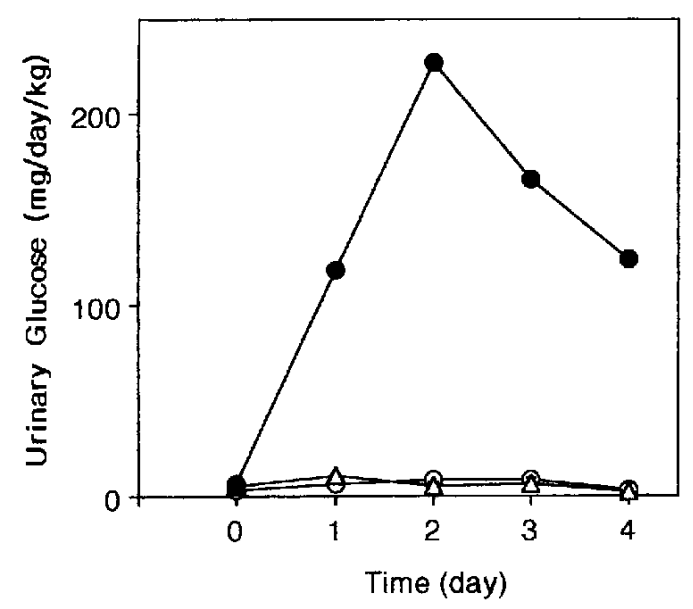

Fig. 2. Changes in urinary protein and urinary glucose in rabbits following administration of panipenem (PAPM) with or without betamipron (BP). Each point represents the mean value of three rabbits. O: PAPM (200 mg/kg), O: PAPM/BP (200 $\mathrm{mg} / \mathrm{kg}: 200 \mathrm{mg} / \mathrm{kg}$ ), $\triangle$ : control (saline). 


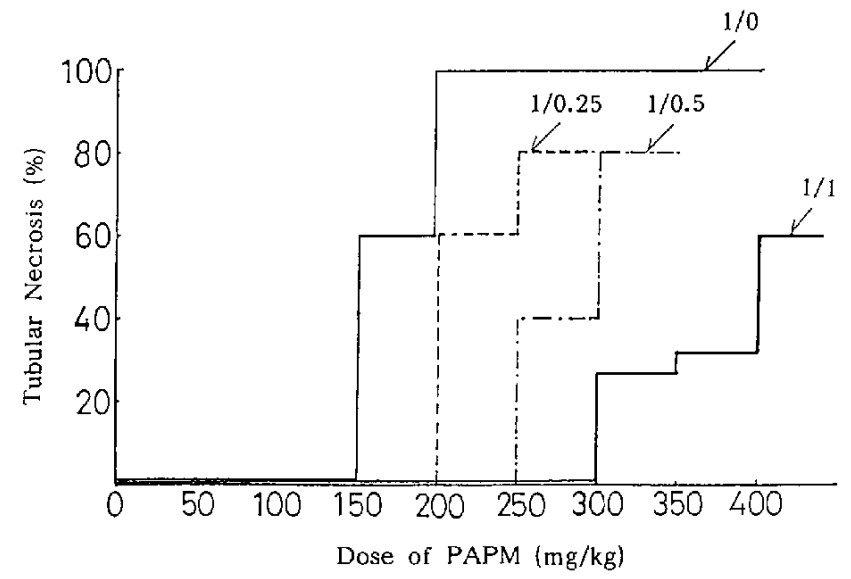

Fig. 3. Relationships between intensity of tubular necrosis and dose ratios of panipenem (PAPM) and betamipron (BP). Each value represents the mean of three rabbits. The tubular necrosis was evaluated using the classification of $0,20,40,60,80$ and $100 \%$ (tubular necrosis) according to the procedure described in Materials and Methods. $1 / 0,1 / 0.25,1 / 0.5$ or $1 / 1$ indicates the dose ratio of PAPM against BP.

\section{Inhibitory effect of BP on carbapenem uptake in rabbit renal cortex}

The concentration-time profiles of PAPM and BP in the rabbit renal cortex after each intravenous dose of 100 $\mathrm{mg} / \mathrm{kg}$ are shown in Figs. 4 and 5. Both PAPM and BP were accumulated in the renal cortex immediately after the intravenous administration. The uptake of PAPM into the renal cortex was remarkably inhibited by simultaneous treatment with BP (Fig. 4). However, the uptake of BP was not influenced by the coadministration of PAPM (Fig. 5). The treatment with BP tended to inhibit

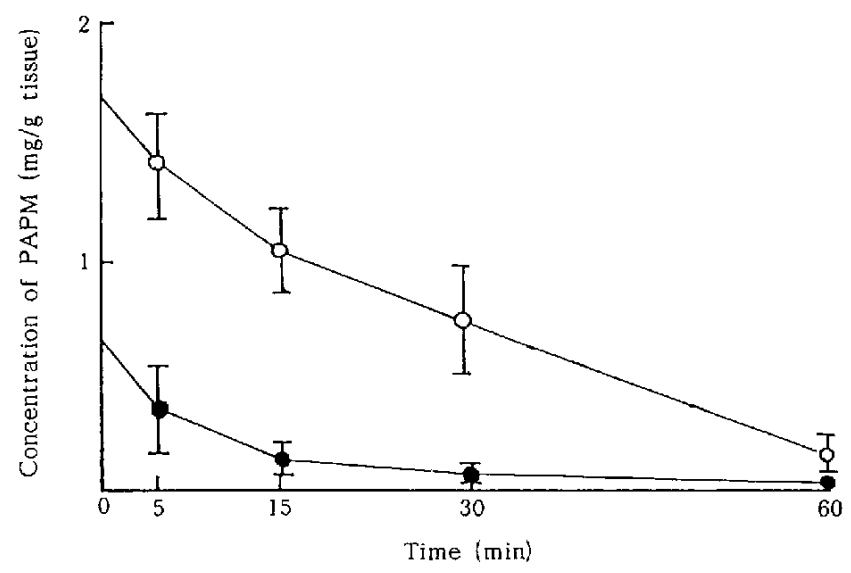

Fig. 4. Renal accumulation-time profiles of panipenem (PAPM) in rabbits. The accumulated amounts of PAPM in the renal cortex were examined following intravenous administration of $100 \mathrm{mg} / \mathrm{kg}$ of PAPM with (O) or without $(\bigcirc) 100 \mathrm{mg} / \mathrm{kg}$ of BP. Each point represents the mean \pm S.E. of three rabbits.

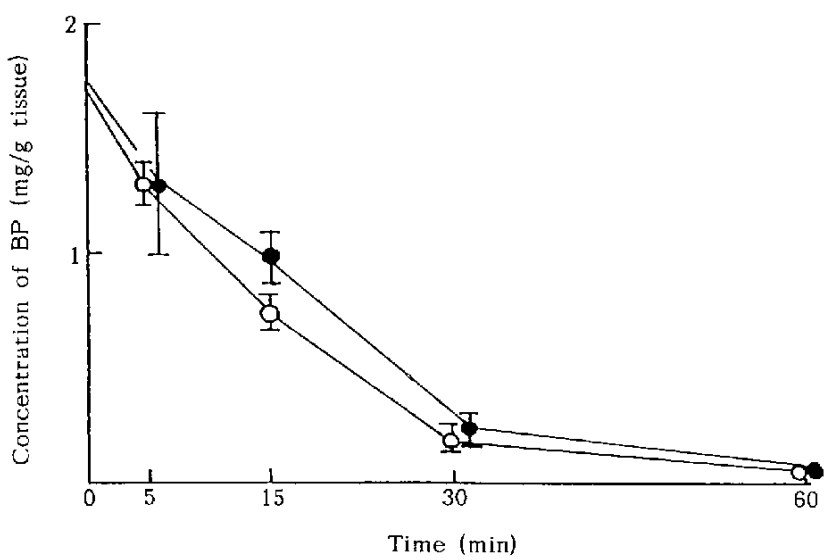

Fig. 5. Renal accumulation-time profiles of betamipron (BP) in rabbits. The accumulated amounts of $\mathrm{BP}$ in the renal cortex were examined following intravenous administration of $100 \mathrm{mg} / \mathrm{kg}$ of BP with (O) or without (O) $100 \mathrm{mg} / \mathrm{kg}$ of PAPM. Each point represents the mean \pm S.E. of three rabbits.

the uptake of PAPM and IPM into the renal cortex. However, the plasma levels of both PAPM and IPM were not changed by the treatment with BP (Fig. 6).

The correlation between dose and renal accumulation of PAPM and BP were studied. The accumulation of PAPM in the renal cortex was apparently saturated at doses of more than $200 \mathrm{mg} / \mathrm{kg}$, i.v. (Fig. 7), whereas the accumulation of BP increased dose-dependently up to a dose of $800 \mathrm{mg} / \mathrm{kg}$, i.v. (Fig. 8). This finding was consistent with the results on the tubular necrosis shown in Fig. 3. That is, the minimal dose of PAPM that induced approximately $100 \%$ tubular necrosis was consistent with
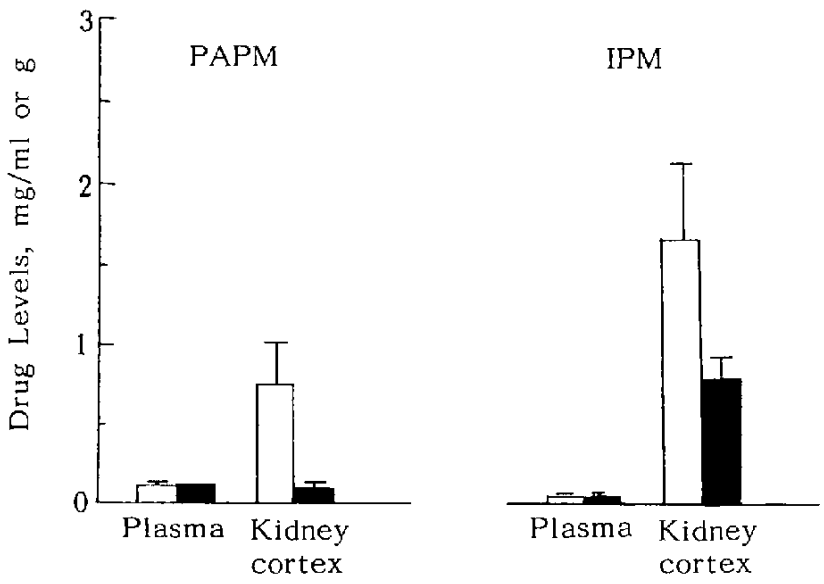

Fig. 6. Renal accumulation and plasma levels of panipenem (PAPM) and imipenem (IPM) in rabbits. The renal accumulation and plasma levels of PAPM and IPM were examined 30 min after intravenous administration of $100 \mathrm{mg} / \mathrm{kg}$ of PAPM or IPM with ( or without $(\square) 100 \mathrm{mg} / \mathrm{kg}$ of BP. Each point represents the mean $\pm S$.E. of three rabbits. 


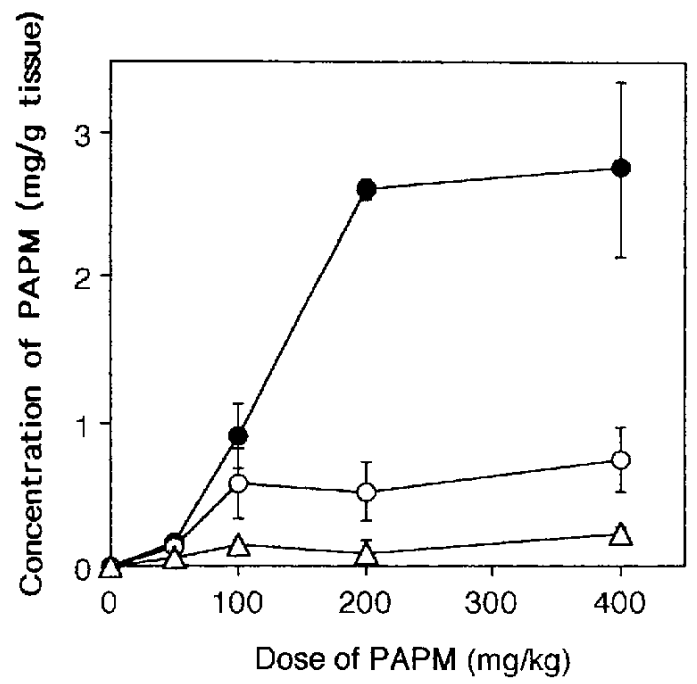

Fig. 7. Accumulation capacity of panipenem (PAPM) in rabbit renal cortex. The accumulated amounts of PAPM were examined $30 \mathrm{~min}$ after intravenous administration of PAPM with $\bigcirc$ : $\mathrm{PAPM} / \mathrm{BP}, 1: 0.5 ; \triangle: \mathrm{PAPM} / \mathrm{BP}, 1: 1)$ or without (O) BP as a function of different PAPM doses and combination ratios. Each point represents the mean \pm S.E. of three rabbits.

the minimal dose of PAPM that showed saturated accumulation in the renal cortex. Therefore, the intravenous dose of $200 \mathrm{mg} / \mathrm{kg}$ PAPM was concluded to be sufficient to produce severe tubular necrosis in rabbits. The accumulated amount of PAPM in the renal cortex was also reduced significantly by the treatment with BP dose-dependently.

\section{DISCUSSION}

Carbapenems generally have very low toxicity in most experimental animals. However, some species of experimental animals show acute renal dysfunction if given these drugs at a dose much above that required clinically. Histological changes induced by large doses of PAPM and IPM (4) were similar in their location, morphologic appearance and rate of occurrence to those induced by CER in rabbits and monkeys. The degree of renal damage by the carbapenems $(4)$ and CER $(5,6)$ and the dose necessary to produce renal damages vary among animal species. Rabbits were the most sensitive to the nephrotoxicity of carbapenems.

The results in the single-dosing study of the carbapenems and CER in rabbits showed that the doses of CER, IPM and PAPM necessary to produce the proximal tubular necrosis were less than $75 \mathrm{mg} / \mathrm{kg}, 100 \mathrm{mg} / \mathrm{kg}$ and 150 $\mathrm{mg} / \mathrm{kg}$, respectively (Fig. 1). Urinary levels of protein and glucose rapidly increased until two days after a single intravenous dose of $200 \mathrm{mg} / \mathrm{kg}$ PAPM, and they slowly decreased thereafter (Fig. 2). These results indicate that

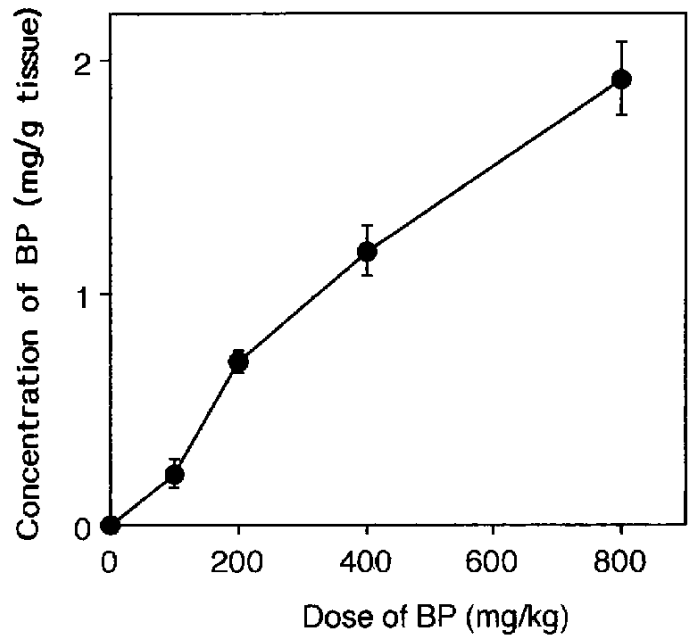

Fig. 8. Accumulation capacity of betamipron (BP) in rabbit renal cortex. The accumulated amounts of BP were examined $30 \mathrm{~min}$ after intravenous administration. Each point represents the mean \pm S.E. of three rabbits.

the renal damage induced by high doses of PAPM is acute renal dysfunction, although it was reversible in many cases.

The renal cortical accumulation of PAPM was saturated at doses of antibiotic greater than $200 \mathrm{mg} / \mathrm{kg}$, i.v. (Fig. 7). This result suggests that the intracellular accumulation capacity of PAPM was relatively small, but the saturated concentration of the antibiotic in the tubular cells was sufficient to induce renal injury, including proximal tubular necrosis. In contrast, the accumulated amount of $\mathrm{BP}$ increased dose-dependently up to at least the intravenous dose of more than $800 \mathrm{mg} / \mathrm{kg}$ (Fig. 8). This result suggests that BP has relatively low affinity to a protein like a carrier protein or BP transported into the renal cortex is immediately excreted. In fact, it was shown that BP strongly inhibited the renal secretion of CER in our previous study (1). In addition, it was shown that the treatment with BP significantly inhibited the uptake of PAPM and IPM into the renal cortex without changing their plasma levels (Fig. 6). In a previous paper (2), we suggested the following reason for this: The treatment with BP significantly inhibited the uptake of the carbapenems into the renal cortex, but scarcely altered their pharmacokinetics. This is considered to be the reason why the secreted amounts of carbapenems were not due to their protein binding and also did not influence their distribution volumes after treatment of BP (2).

$\mathrm{BP}$ also inhibited the renal cortical accumulation of IPM. It has been reported that IPM-induced nephrotoxicity is reduced by the coadministration of cilastatin (3). BP does not exhibit inhibitory activity against DHP-I (7), which exists in tubular cells and inactivates the carbap- 
enems by breaking the $\beta$-lactam bond, whereas cilastatin has high inhibitory activity against DHP-I. These results suggest that BP may be able to prevent the nephrotoxicity induced by carbapenems. It can be recognized that BP is a novel organic anion transport inhibitor in renal tubules and is very useful for reducing the carbapenem-induced nephrotoxicity because of its efficacy and safety. BP is expected to be a novel candidate for reducing the nephrotoxicity induced by $\beta$-lactam antibiotics, including carbapenems and cephalosporins.

\section{Acknowledgments}

The authors are deeply grateful to Drs. M. Fukami and J. Fukushige for preparations of histological specimens and their valuable advice.

\section{REFERENCES}

1 Hirouchi Y, Naganuma H, Kawahara Y, Okada R, Kamiya A, Inui $\mathbf{K}$ and Hori R: Protective effect of $\mathrm{N}$-acyl amino acids (NAAs) on cephaloridine (CER) nephrotoxicity in rabbits. Jpn J Pharmacol 63, 487-493 (1993)

2 Naganuma $H$, Hirouchi $Y$, Kawahara $Y$, Inui $K$, Tanigawara $Y$,
Yasuhara M, Hori R and Kuwahara S: Nephroprotective effect and its mechanism of betamipron (2). Chemotherapy 39, S-3, $178-189$ (1991)

3 Norrby SR, Alestig K, Björnegard B, Burman LA, Ferber F, Huber JL, Jones KH, Kahan FM, Kahan JS, Kropp $\mathbf{H}$, Meisinger MAP and Sundelof JG: Urinary recovery of $N$-formimidoyl thienamycin (MK0787) as affected by coadministration of $N$-formimidoyl thienamycin dehydropeptidase inhibitors. Antimicrob Agents Chemother 23, 300-307 (1983)

4 Birnbaum J, Kahan FM, Kropp H and Macdonald JS: Carbapenems, a new class of beta-lactam antibiotics. Discovery and development of imipenem/cilastatin. Am J Med 78, Supp 6A, 3-21 (1985)

5 Atkinson RM, Currie JP, Davis B, Pratt DA, Sharpe HM and Tomich EG: Acute toxicity of cephaloridine, an antibiotic derived from cephalosporin C. Toxicol Appl Pharmacol 8, $398-406$ (1966)

6 Fleming PC and Jaffe D: The nephrotoxic effect of cephaloridine. Postgrad Med J, Supp 43, 89-90 (1967)

7 Naganuma $H$, Tokiwa $H$, Hirouchi $Y$, Kawahara $Y$, Fukusige J, Fukami M, Hirota K, Muramatsu S, Takahagi H, Inui K, Tanigawara $Y$, Yasuhara $M$, Hori $R$ and Kuwahara S: Nephroprotective effect and its mechanism of betamipron (1). Chemotherapy 39, S-3, 166-177 (1991) 